\title{
Osseous Remodeling After Femoral Head-neck Junction Osteochondroplasty
}

\author{
Nader A. Nassif MD, Murat Pekmezci MD, \\ Gail Pashos BS, Perry L. Schoenecker MD, \\ John C. Clohisy MD
}

Published online: 18 September 2009

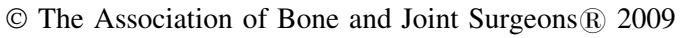

\begin{abstract}
Femoral head-neck junction osteochondroplasty is commonly used to treat femoroacetabular impingement, yet remodeling of the osteochondroplasty site is not well described. We therefore describe bony remodeling at the osteochondroplasty site and analyze clinical outcomes and complications associated with femoral osteochondroplasty. We retrospectively reviewed 135 patients (150 hips) who underwent femoral head-neck osteochondroplasty combined with hip arthroscopy, surgical hip dislocation, periacetabular osteotomy, or proximal femoral osteotomy. The minimum clinical followup was 10 months (mean, 22.3 months; range, 10-65 months). We assessed the femoral-head neck offset, head-neck offset ratio, alpha angle, and cortical remodeling. We used the Harris hip score to determine hip function. We observed an increase in the head-neck offset, offset ratio, and decrease in the alpha angle postoperatively and at latest followup. Ninety-eight of $113(87 \%)$ hips had partial or complete recorticalization at the osteochondroplasty site. The mean Harris hip score
\end{abstract}

One or more of the authors have received funding from Award Number UL1RR024992 from the National Center for Research Resources (JCC) and the Curing Hip Disease Fund (JCC).

The content is solely the responsibility of the authors and does not necessarily represent the official views of the National Center for Research Resources or the National Institutes of Health.

The Institutional Review Board has approved the human protocol for this investigation, that all investigations were conducted in conformity with ethical principles of research, and informed consent was obtained.

N. A. Nassif, M. Pekmezci, G. Pashos, P. L. Schoenecker, J. C. Clohisy ( $\square)$

Department of Orthopaedic Surgery, Washington University

School of Medicine, One Barnes-Jewish Hospital Plaza,

Suite 11300 West Pavilion, St Louis, MO 63110, USA

e-mail: jclohisy@wustl.edu; clohisyj@wudosis.wustl.edu improved from 64 to 85 . We excised heterotopic bone in one hip. There were no femoral neck fractures. The deformity correction achieved with femoral head-neck osteochondroplasty is maintained and recorticalization occurs in the majority of cases during the first two years.

Level of Evidence: Level IV, therapeutic study. See Guidelines for Authors for a complete description of levels of evidence.

\section{Introduction}

Femoroacetabular impingement (FAI) is a recognized cause of hip dysfunction in the young adult hip and may result in hip osteoarthritis [2, 19]. Ganz et al. demonstrated abnormal anatomy results in excessive contact pressures and microtrauma leading to articular cartilage damage $[2,19,24,38]$. Femoroacetabular impingement lesions can be either femoral-sided (cam impingement) resulting from a reduced head-neck offset or an aspheric femoral head $[19,24]$ or acetabular-sided (pincer impingement) in which there is excessive acetabular coverage of the femoral head $[19,25,37]$. Combined femoral and acetabular-sided lesions are also common $[2,16]$.

Since recognition of FAI has become more commonplace, efforts have focused on improved methods of diagnosis and treatment. The best methods of surgical treatment, however, remain controversial and continue to be refined. Recontouring of the femoral head-neck junction to increase the offset is a fundamental aspect of surgical management for cam-type impingement [3], whereas acetabular overcoverage is addressed with trimming of the acetabular rim and infrequently acetabular reorientation $[15,16,26]$. Several operations have been described to address the femoral-sided pathology. Ganz et al. described 
a safe and effective surgical hip dislocation that minimizes the danger of vascular insult to the femoral head, which allows direct access to the femoral head and neck for performing the osteochondroplasty [17]. Several others have also described limited open [11, 27] and entirely arthroscopic methods [23, 26, 35] for addressing femoral and/or acetabular lesions. There is a growing body of evidence that demonstrates improved clinical outcomes after treatment of FAI [1, 7, 20]. Beaule et al. showed improvement in the UCLA and WOMAC 3 years after surgical dislocation and osteochondroplasty [1], whereas Byrd et al. reported substantial clinical improvement in the Harris hip score after arthroscopic osteochondroplasty of the head-neck junction [7]. These studies thus far suggest a minimal complication rate with FAI surgery. These studies, however, provide limited data regarding complications after recontouring of the femoral head-neck junction and do not describe bony remodeling of the osteochondroplasty site [7, 22].

The primary focus of our study was therefore to (1) describe radiographic bony remodeling after osteochondroplasty of the femoral head-neck junction; (2) report clinical outcomes as they relate to bony remodeling, specifically recorticalization and change in the alpha angle; (3) describe the complications and reoperations after osteochondroplasties of the femoral head-neck junction.

\section{Patients and Methods}

We retrospectively reviewed 163 patients (178 hips) who underwent femoral head-neck osteochondroplasty either exclusively or in association with other procedures from October 2004 to December 2006 (Fig. 1). The average age of the included patients at the time of surgery was 32.7 years (range, 15-56 years). Minimum clinical followup was 10 months (mean, 22.3 months; range, 1065 months). Nineteen hips (10.6\%) were lost to followup before 1 year. Four hips (2.2\%) were converted to a total hip or resurfacing arthroplasty in less than 12 months. Two patients $(1.1 \%)$ were unable to participate in the study owing to other medical issues. Three hips $(1.6 \%)$ with major proximal femoral head deformity treated with proximal femoral osteotomies (PFO) and head-neck osteochondroplasty were later excluded from the study as a result of the severity of their deformity. Therefore, we reviewed 135 patients (150 hips) (Table 1). One hundred five patients (113 hips) had radiographic and clinical data; 30 additional patients (37 hips) had inadequate radiographic data but full clinical followup. The minimum radiographic followup was 8 months (mean 20 months; range, 8-54 months). We obtained prior Institutional Review Board approval.

Table 1. Patient demographics

\begin{tabular}{ll}
\hline Patient characteristic & Number \\
\hline Patients with radiographic and clinical data (hips) & $105(113)$ \\
Patients with clinical followup (hips) & $30(37)$ \\
Males (\%) & $70(51.4 \%)$ \\
Females (\%) & $65(48.6 \%)$ \\
Mean age at the time of surgery (years; range) & $32.7(15.2-55.5)$ \\
\hline Procedures & Number of hips (\%) \\
\hline Osteochondroplasty (limited open) & $90(60 \%)$ \\
PAO with limited open OCP & $40(26.6 \%)$ \\
Surgical dislocations & $17(11.4 \%)$ \\
PAO/PFO & $3(2.0 \%)$
\end{tabular}

$\mathrm{PAO}=$ periacetabular $\quad$ osteotomy $; \quad \mathrm{OCP}=$ osteochondroplasty; $\mathrm{PFO}=$ proximal femoral osteotomy
Fig. 1 Flow diagram demonstrating the included and excluded patients from the initial group of patients reviewed. HRA $=$ hip resurfacing arthroplasty.

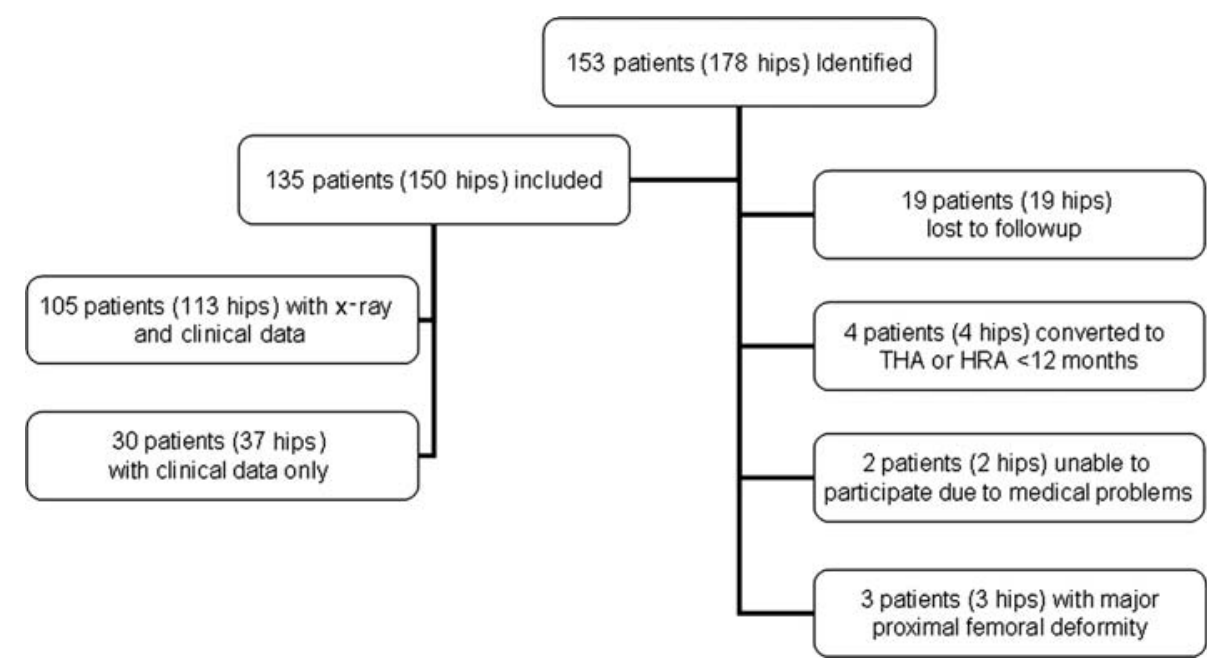


Fig. 2A-B (A) The head-neck offset (HNO) was measured in a preoperative measurement on a frog leg lateral view. Line 1 is drawn to bisect the femoral neck. Parallel lines are draw tangential to the femoral neck (Line 2) and the femoral neck (Line 3). The $\mathrm{HNO}$ is the measurement of the distance between Lines 2 and 3 . (B) An example demonstrates the measurement of the same patient after the osteochondroplasty. The circle template allows for consistent measurement across time points.
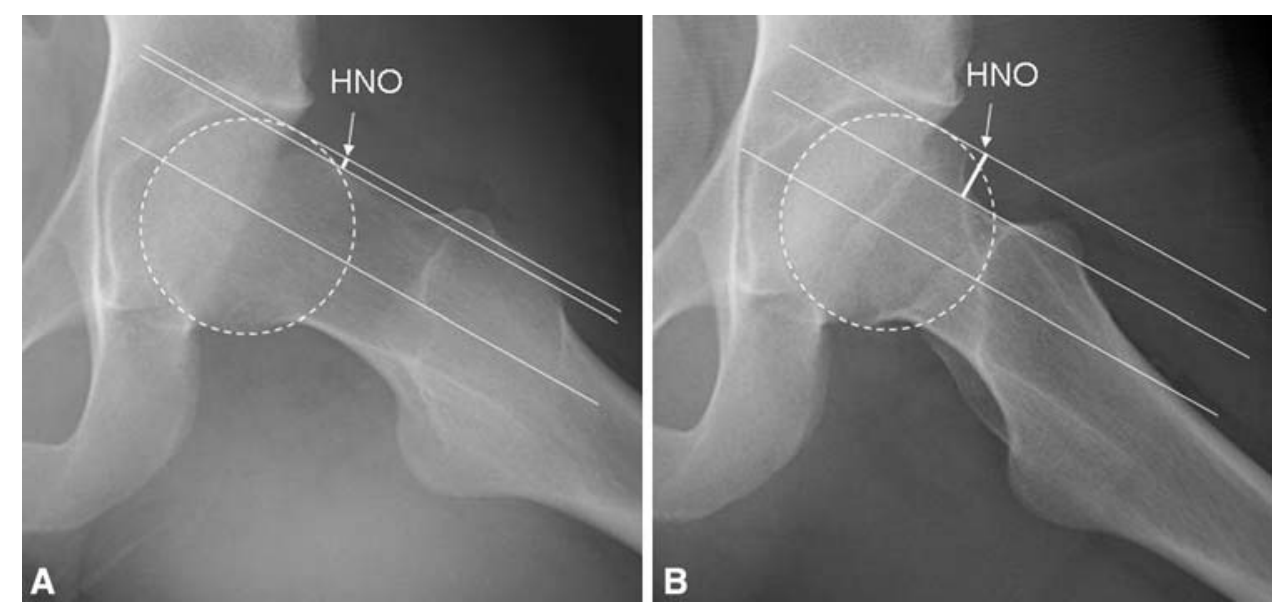

All surgery was performed by one surgeon (JCC). Ninety hips with isolated FAI were treated with hip arthroscopy and limited open osteochondroplasty of the femoral head-neck junction for a cam-type lesion. Forty hips had a periacetabular osteotomy (PAO) for symptomatic acetabular dysplasia with an osteochondroplasty to prevent secondary impingement $[12,29]$. Seventeen hips underwent surgical hip dislocation to address combined cam and pincer-type deformity, major pincer abnormalities, or severe femoral head deformities. Three additional hips with acetabular dysplasia and severe proximal femoral deformities underwent PAO as well a PFO with reshaping of the femoral head-neck junction. We performed hip arthroscopy using standard anterior, anterolateral, and posterolateral portals $[5,6,11,35]$. After diagnostic arthroscopy and débridement of the labrum as necessary, limited anterior arthrotomy and osteochondroplasty were performed through a standard anterior approach to the hip. We performed periacetabular osteotomies as described by Ganz et al. [8, 9, 18, 28]. After the osteotomy, anterior arthrotomy and recontouring of the femoral head-neck junction was carried out to reduce the risk of secondary impingement. Surgical hip dislocations were performed as described by Ganz et al. [17]. After the capsule was opened, the hip was dislocated and examined and the femoral head-neck offset restored. For all procedures, labral tears were débrided and repaired or resected as necessary. Forty-eight patients had acetabular cartilage defects for which we performed chondroplasty. Five patients had microfracture of their acetabular cartilage defect. Twelve patients had additional acetabular rim trimming. Intraoperative examination of the range of motion was performed routinely to ensure adequate impingement-free range of motion.

Postoperative rehabilitation required patients to be toetouch weightbearing for a 6-week period. During that time, physical therapy focused on gentle range of motion and isometric exercises. After the 6-week period, patients progressed to weightbearing as tolerated with increasing stretching and strengthening. Patients were allowed to return to full sports activity at 4 months as tolerated.

Radiographic data were available for 105 patients (113 hips). The osteochondroplasty site was analyzed on the frog lateral radiographs. Ninety-two patients (100 hips) had preoperative frog lateral radiographs. One hundred five hips had postoperative radiographs and 109 hips followup radiographs. Postoperative films were obtained on the first followup visit rather than immediately after the procedure. All radiographic variables were measured serially by one observer (NAN) according to our previously published techniques [10, 13, 32]. All measurements were performed using the EVMS Advanced Visualization Software, which has a measurement precision to the one-hundredth decimal place (Emageon Inc, Birmingham, AL).

The head-neck offset (HNO) was measured based on the method previously described by Eijer et al. [14] on the frog leg lateral radiograph (Fig. 2). Initially, a line was drawn so it was parallel and bisected the femoral neck irrespective of its location on the femoral head. A second line parallel to the first was drawn tangential to the anterolateral neck on the frog leg view. A third line, parallel to the first and second lines, was drawn tangential to the femoral head. The HNO was determined by measuring the perpendicular distance between the second and third lines. Postoperatively, as a result of the reshaping of the head-neck junction, the second line was drawn tangential to the proximal portion of the femoral neck; the third line was drawn tangential to the most anterolateral aspect of the femoral head as indicated by a circle template to ensure the measurement was consistent with the preoperative femoral head shape. A normal HNO is greater than $9 \mathrm{~mm}$ [14]. The $\mathrm{HNO}$ in the preoperative and followup radiographs was normalized to the femoral head diameter in postoperative films, which allows for more direct comparisons between HNO between time points. The head-neck offset ratio (HNOR) was also calculated to account for error 
introduced by magnification differences across time points. The HNO was divided by the head diameter measured at every time point (preoperatively, immediately postoperatively, and at latest followup). The HNO measurement reportedly has a high intraobserver and a moderate interobserver reliability [13].

We measured the alpha angle as previously described by Notzli et al. [31] at every time point (Fig. 3). A line was drawn through the longitudinal axis of the femoral neck. A circular template was drawn to match the diameter of the femoral head. A line was drawn from the center of the head through the point where the femoral head deviates from the circular template. After the osteochondroplasty, the alpha angle was determined by the point where the femoral head intersected the circular template. Ideally, this fell at the intersection of the resected area and femoral neck. The alpha angle in normal hips is approximately $42^{\circ}$. Measurement of the alpha angle reportedly has high inter- and intraobserver reliability [13].

The degree of recorticalization at the osteochondroplasty site was also evaluated (Fig. 4). If no evidence of recorticalization was present when comparing immediate postoperative films and the latest followup films, it was graded as "none." If evidence of sclerosis of the bone margin was observed but was incomplete, it was graded as "partial." If there was a continuous cortical line between the femoral head and head-neck junction, the sample was graded as "complete." The degree of heterotopic ossification was determined as described by Brooker et al. [4].

Patients were evaluated at 6 weeks for their first postoperative followup, then at 12-week, 6-month, 1-year, and 2-year intervals. We obtained Harris hip scores [21] preoperatively and at annual followups. All patients included had a preoperative Harris hip score and all had an annual followup hip score. Patients who developed surgical site infections, fractures, avascular necrosis, or any repeat surgery were noted.

Longitudinal analyses for HNO, HNOR, and alpha angle that were measured at more than two time points were carried out using mixed model repeated measures analyses of variance with available data from each participant. As a result of heterogeneity of variance and lack of normality,
Fig. 3A-B (A) The alpha angle is measured by applying a circular template to match the diameter of the femur. A line is drawn along the longitudinal axis of the femoral neck. A second line is drawn from the center of the circular template to the point where the femoral head deviates from the circular template. The angle subtended by these lines forms the alpha angle. (B) Example of improved alpha angle after recontouring of the femoral headneck junction is shown.

Fig. 4A-C The recorticalization of the femoral head-neck junction was assessed by comparing postoperative and followup films. They were labeled (A) "none" if no sclerotic margin was noted at the resection site and (B) "partial" if sclerosis was present but was incomplete. (C) If there was a continuous cortical line between the femoral head and the headneck junction, the sample was graded as "complete." The arrow indicates the location of bone resection.
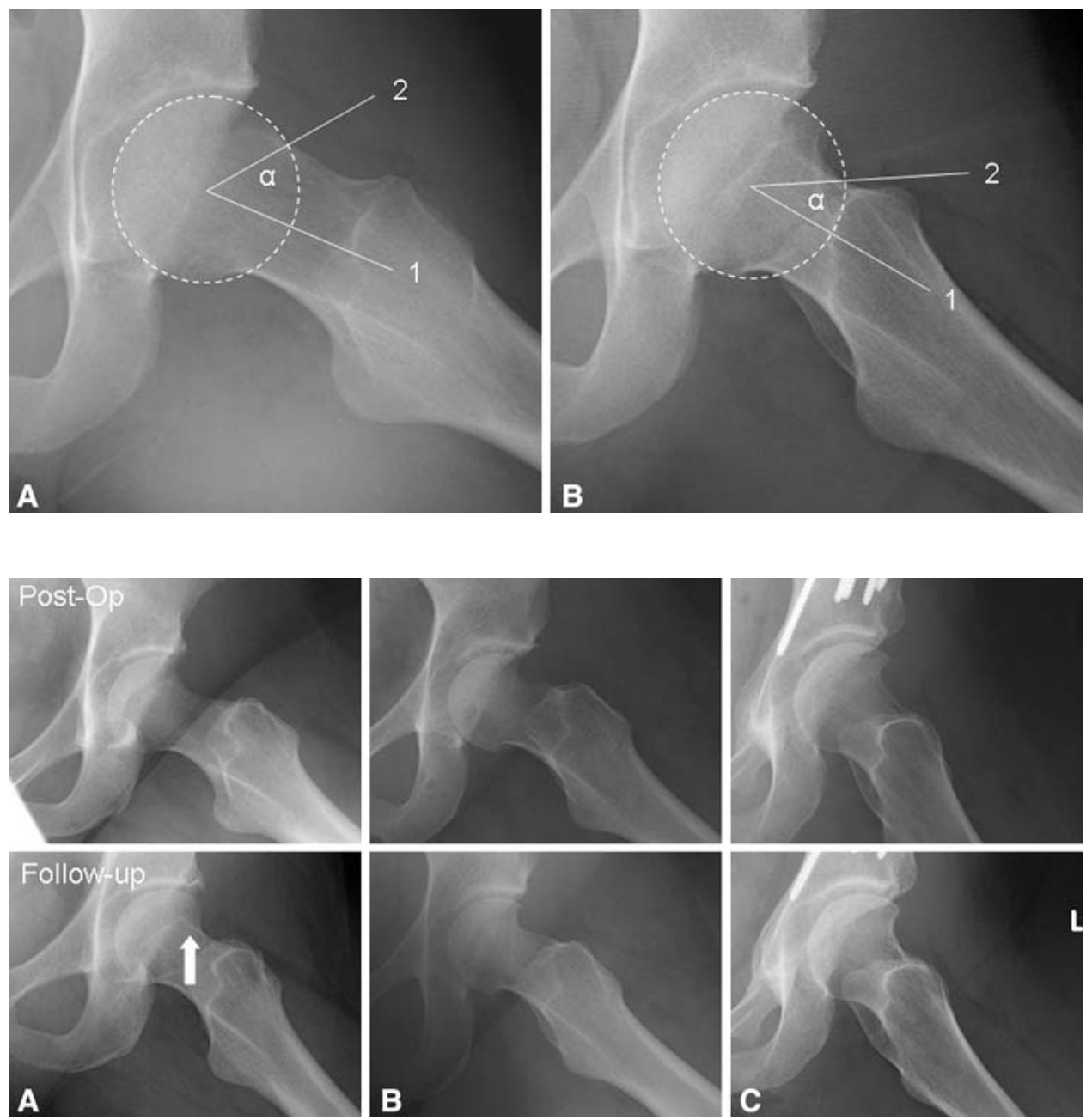
data were rank-transformed before analysis. The KruskalWallis test was used to compare the three recorticalization groups. A paired t-test was used to compare Harris hip preoperative scores with followup scores. A Spearman correlation was performed between recorticalization and Harris hip score as well as alpha angle and Harris hip score. The data analysis was generated using SAS software (Version 9.1.3, SAS Institute Inc, Cary, NC).

\section{Results}

We observed improvement in all radiographic femoral based impingement parameters at short-term followup (Fig. 5). HNO increased ( $<0.0001)$ from $3.7 \pm 4.0 \mathrm{~mm}$ preoperatively to $9.6 \pm 2.4 \mathrm{~mm}$ postoperatively and increased $(\mathrm{p}=0.008)$ further to $10.3 \pm 2.8 \mathrm{~mm}$ at latest followup. The HNOR increased $(\mathrm{p}<0.0001)$ from $0.08 \pm$ 0.07 to $0.17 \pm 0.04$ postoperatively and increased $(\mathrm{p}=0.0009)$ to $0.19 \pm 0.04$ at latest followup. The alpha angle decreased $(\mathrm{p}<0.0001)$ from $60^{\circ} \pm 17^{\circ}$ to $42^{\circ} \pm 6^{\circ}$ and continued to improve $(\mathrm{p}=0.02)$ to $40^{\circ} \pm 7^{\circ}$ in followup. At last followup, we observed partial corticalization in 88 of the 113 hips for which data were available; complete recorticalization occurred in 10 hips and 15 hips had no recorticalization. We observed no difference $(\mathrm{p}=0.14)$ in followup times between those who showed complete recorticalization (mean 16.58) and those who showed no recorticalization (mean 18.62).

Overall, the Harris hip score improved from a mean of $64 \pm 14$ preoperatively to a mean of $85 \pm 16$ at last followup. Six hips $(4 \%)$ that underwent additional surgery were excluded from this analysis and are discussed subsequently. For patients who had radiographic and clinical data, there was no correlation $(\mathrm{p}=0.34)$ noted between Harris hip scores and recorticalization (Fig. 6).

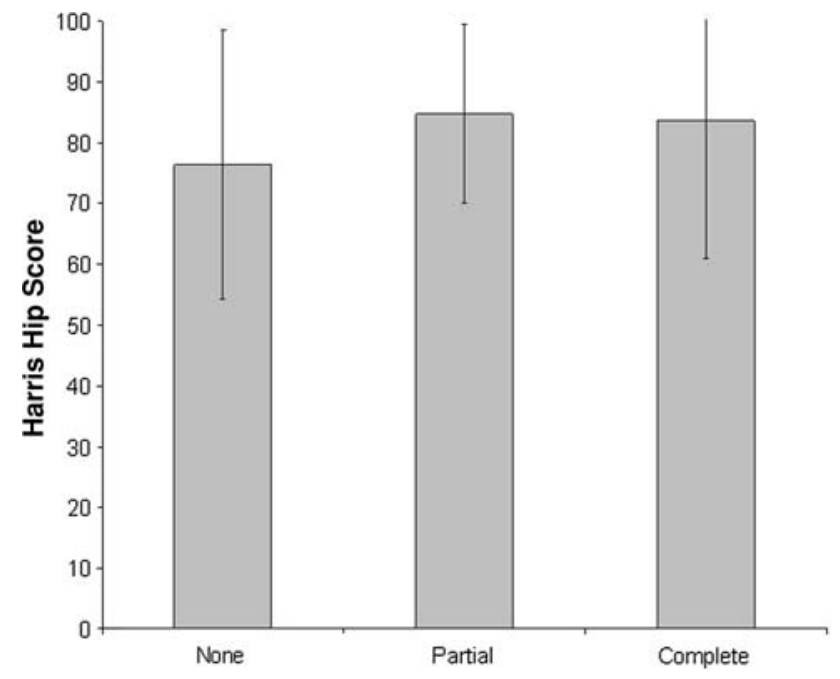

Fig. 6 We observed no correlation $(p=0.34)$ between the Harris hip score and degree of recorticalization.

Additionally there was no correlation $(\rho=-0.09$, $\mathrm{p}=0.37$ ) between improvement in Harris hip scores and postoperative alpha angles. Few major complications were found in this case series. One patient with Grade II heterotopic ossification after a PAO had continued pain for which we performed surgical excision with good relief. There were no incidents of deep surgical site infection, femoral neck fractures, or avascular necrosis of the femoral head observed over the duration of this study. Five patients underwent revision surgery for persistent hip pain; in two of these, we presumed the cause of the pain was persistent impingement. The first was a 39-year-old man with a history of FAI who continued to have intermittent hip pain after his initial hip arthroscopy. He underwent repeat hip arthroscopy and osteochondroplasty 5 years after his initial procedure and had complete resolution of pain. The second patient was a 22-year-old woman with FAI and coxa valga
Fig. 5 There was a decrease of the alpha angle and increase of the headneck offset (HNO) and head-neck offset ratio (HNO ratio).

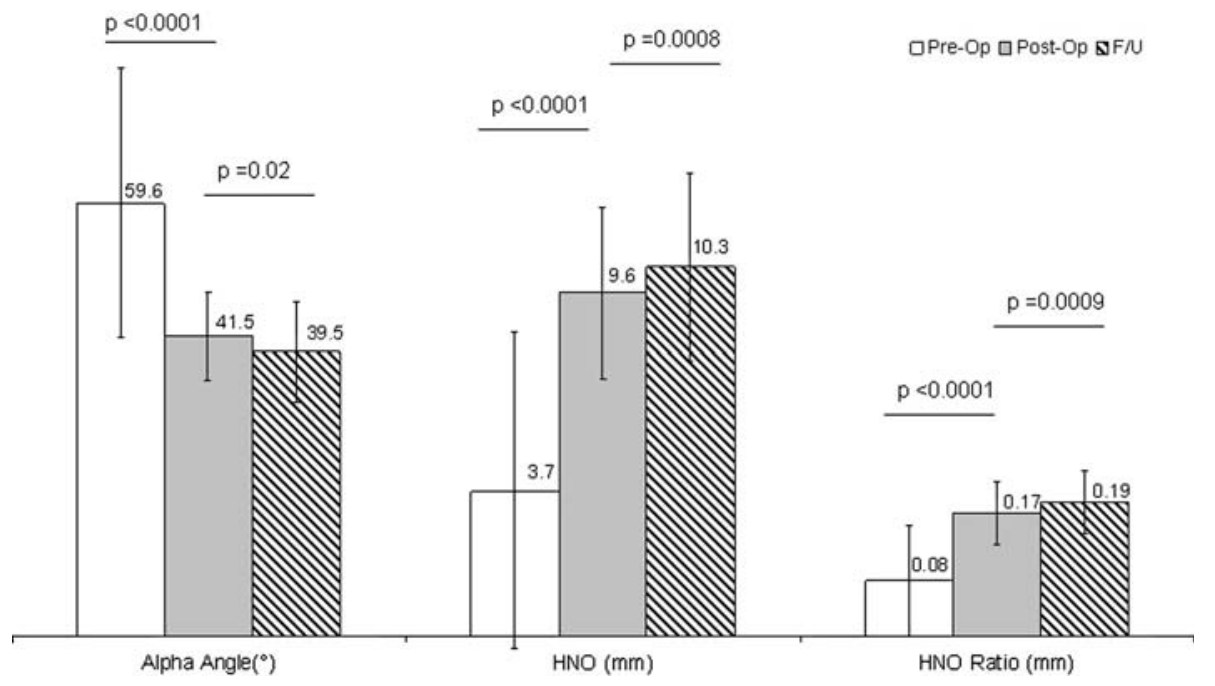


who had a varus-producing PFO 6 months after her initial hip arthroscopy and osteochondroplasty. The PFO was performed to address excessive anterolateral instability of the femoral head. We believe instability was a component of her initial problem, not secondary to the osteochondroplasty. One patient had repeat hip arthroscopy for adhesiolysis of intracapsular scarring. Two patients had total hip and hip resurfacing at 3 and 4 years, respectively, for progressive secondary osteoarthritis.

\section{Discussion}

Osteochondroplasty of the femoral head-neck junction is a common component of hip impingement surgery, yet there is minimal literature describing the bony remodeling, clinical consequences, and specific complications associated with this technique. This study aims to (1) elucidate bony remodeling after osteochondroplasty of the femoral head-neck junction; (2) assess the clinical outcomes as it correlates to evidence of radiographic healing; and (3) report complications and reoperations after osteochondroplasty of the femoral head-neck junction.

This study does have several limitations. First, the heterogeneity of the abnormalities and the procedures performed are confounding variables. Our cohort included patients with a variety of structural abnormalities. This may contribute to the large variability in the HNO seen preoperatively. This heterogeneity, however, does allow for the generalizability of the results in regard to remodeling of head-neck osteochondroplasty because this study specifically focused on the osteochondroplasty site in radiographic evaluation. Second, we lost 19 patients (11\%) to followup despite attempts to contact these patients. The large cohort examined, however, provides adequate data to support our observations with respect to bony remodeling, but a longer followup time would be needed to assess the continued remodeling we observe. Third, because our main focus was the radiographic evaluation of the osteochondroplasty site, acetabular-sided abnormalities, although commonly addressed during surgery, were not specifically examined in the setting of healing of the osteochondroplasty site. Fourth, the radiographic assessment of recorticalization was assessed by only one trained observer. There are no intraobserver or interobserver reliability data available for determining the recorticalization of the chondroplasty site. Slight variations in the xray projection may also influence the ability to assess recorticalization. This error is minimized by obtaining our radiographs by specialized musculoskeletal radiology technicians using standard techniques and projections.

Our primary objective was to assess the remodeling of the osteochondroplasty site. The data suggest we consistently achieved surgical correction of the head-neck junction as determined by the HNO and alpha angle. We also demonstrated partial or complete recorticalization in $87 \%$ of the resection sites. Although to our knowledge, no study has examined recorticalization of the femoral headneck junction, one recent study by Neumann et al. examined the alpha angle correction in a cohort of 45 patients followed for 2 years [30]. Their study demonstrated a mean correction to $43^{\circ}$, which was maintained over the 2-year followup period. Our study demonstrated similar correction of the alpha angle to an average of $42^{\circ}$. One unexpected result in our larger cohort of patients, however, was the continued improvement of the HNO and alpha angle that was noted at final followup when compared with postoperative radiographs. We speculate there will be continued remodeling and resorption at the osteochondroplasty site that is ongoing up to 2 years postoperatively. Characterizing and understanding the mechanism of that remodeling would merit further investigation.

Several groups have previously demonstrated improved functional outcomes after treatment of FAI. Patients in these series were treated with surgical dislocations [1, 3, 15, 16, 33], hip arthroscopy, and combined limited open osteochondroplasty $[11,27]$ or all arthroscopic osteochondroplasty [7, 23, 34, 36]. Our data present similar improvements in hip function scores compared with these previous reports. The heterogeneity of the groups, however, does not allow for direct comparisons between this study and others before it. Additionally, our investigation failed to show any correlation between radiographic correction of FAI (ie, alpha angle) and recorticalization with the Harris hip score. Therefore, the correlation of the deformity with clinical results has not been firmly established in the literature.

We encountered rare $(0.7 \%)$ major complications and reoperation rates $(3 \%)$ were similar to those previously published. A large case series performed by Larson investigated outcomes after arthroscopic management of FAI [26]. In his study of 100 hips, one patient had a symptomatic heterotopic ossification and 3\% underwent THA. There has been only one recent report in the literature of femoral neck fracture after osteochondroplasty of the femoral head neck junction [27]. In a recent review published by Ilizaliturri et al. [22], his group reported an overall complication rate less than $1.5 \%$. They also report inadequate reshaping is the overwhelming reason for revision arthroscopy for FAI.

Our study of osseous remodeling of the head-neck junction after osteochondroplasty demonstrated consistent correction of cam-type impingement lesions as evaluated by the HNO, offset ratio, and alpha angle. This correction was maintained over a mean radiographic followup of 20.1 months. At latest followup, there was continued 
improvement in the $\mathrm{HNO}$, offset ratio, and alpha angle, which suggests continued bony remodeling and resorption may be occurring up to 2 years postoperatively. Bony recontouring and remodeling does not show evidence of regrowth and appears to involve recorticalization of the resected margins in most cases. There was a relatively low complication rate and minimal reoperation rate for impingement. Future investigations will focus on determining optimal parameters for the osteochondroplasty site, including depth and shape. Additionally, longer-term followup will help determine potential long-term hazards of femoral head-neck osteochondroplasty, which theoretically could include femoral neck fractures that may develop with age if complete corticalization is not achieved.

Acknowledgments We thank Karen Steger May for her statistical analysis of the data.

\section{References}

1. Beaule PE, Le Duff MJ, Zaragoza E. Quality of life following femoral head-neck osteochondroplasty for femoroacetabular impingement. J Bone Joint Surg Am. 2007;89:773-779.

2. Beck M, Kalhor M, Leunig M, Ganz R. Hip morphology influences the pattern of damage to the acetabular cartilage: femoroacetabular impingement as a cause of early osteoarthritis of the hip. J Bone Joint Surg Br. 2005;87:1012-1018.

3. Beck M, Leunig M, Parvizi J, Boutier V, Wyss D, Ganz R. Anterior femoroacetabular impingement: part II. Midterm results of surgical treatment. Clin Orthop Relat Res. 2004;418:67-73.

4. Brooker AF, Bowerman JW, Robinson RA, Riley LH Jr. Ectopic ossification following total hip replacement. Incidence and a method of classification. J Bone Joint Surg Am. 1973;55:16291632.

5. Byrd JW. Hip arthroscopy utilizing the supine position. Arthroscopy. 1994;10:275-280.

6. Byrd JW. Hip arthroscopy by the supine approach. Instr Course Lect. 2006;55:325-336.

7. Byrd JW, Jones KS. Arthroscopic femoroplasty in the management of cam-type femoroacetabular impingement. Clin Orthop Relat Res. 2009;467:739-746.

8. Clohisy JC, Barrett SE, Gordon JE, Delgado ED, Schoenecker PL. Periacetabular osteotomy for the treatment of severe acetabular dysplasia. J Bone Joint Surg Am. 2005;87:254-259.

9. Clohisy JC, Barrett SE, Gordon JE, Delgado ED, Schoenecker PL. Periacetabular osteotomy in the treatment of severe acetabular dysplasia. Surgical technique. J Bone Joint Surg Am. 2006;88(Suppl 1):65-83.

10. Clohisy JC, Carlisle JC, Trousdale R, Kim Y, Beaule PE, Morgan P, Steger-May K, Schoenecker PL, Millis M. Radiographic evaluation of the hip has limited reliability. Clin Orthop Relat Res. 2009;467:666-675.

11. Clohisy JC, McClure JT. Treatment of anterior femoroacetabular impingement with combined hip arthroscopy and limited anterior decompression. Iowa Orthop J. 2005;25:164-171.

12. Clohisy JC, Nunley RM, Carlisle JC, Schoenecker PL. Incidence and characteristics of femoral deformities in the dysplastic hip. Clin Orthop Relat Res. 2009;467:128-134.
13. Clohisy JC, Nunley RM, Otto RJ, Schoenecker PL. The frog-leg lateral radiograph accurately visualized hip cam impingement abnormalities. Clin Orthop Relat Res. 2007;462:115-121.

14. Eijer H, Leunig M, Mahomed N, Ganz R. Cross-table lateral radiographs for screening of anterior femoral head-neck offset in patients with femoro-acetabular impingement. Hip Int. 2001;11:37-41.

15. Espinosa N, Beck M, Rothenfluh DA, Ganz R, Leunig M. Treatment of femoro-acetabular impingement: preliminary results of labral refixation. Surgical technique. J Bone Joint Surg Am. 2007;89(Suppl 2):36-53.

16. Espinosa N, Rothenfluh DA, Beck M, Ganz R, Leunig M. Treatment of femoro-acetabular impingement: preliminary results of labral refixation. J Bone Joint Surg Am. 2006;88:925-935.

17. Ganz R, Gill TJ, Gautier E, Ganz K, Krugel N, Berlemann U. Surgical dislocation of the adult hip: a technique with full access to the femoral head and acetabulum without the risk of avascular necrosis. J Bone Joint Surg Br. 2001;83:1119-1124.

18. Ganz R, Klaue K, Vinh TS, Mast JW. A new periacetabular osteotomy for the treatment of hip dysplasias. Technique and preliminary results. Clin Orthop Relat Res. 1988;232:26-36.

19. Ganz R, Parvizi J, Beck M, Leunig M, Notzli H, Siebenrock KA. Femoroacetabular impingement: a cause for osteoarthritis of the hip. Clin Orthop Relat Res. 2003;417:112-120.

20. Graves ML, Mast JW. Femoroacetabular impingement: do outcomes reliably improve with surgical dislocations? Clin Orthop Relat Res. 2009;467:717-723.

21. Harris WH. Traumatic arthritis of the hip after dislocation and acetabular fractures: treatment by mold arthroplasty. An endresult study using a new method of result evaluation. J Bone Joint Surg Am. 1969;51:737-755.

22. Ilizaliturri VM Jr. Complications of arthroscopic femoroacetabular impingement treatment: a review. Clin Orthop Relat Res. 2009;467:760-768.

23. Ilizaliturri VM Jr, Orozco-Rodriguez L, Acosta-Rodriguez E, Camacho-Galindo J. Arthroscopic treatment of cam-type femoroacetabular impingement: preliminary report at 2 years minimum follow-up. J Arthroplasty. 2008;23:226-234.

24. Ito K, Minka MA 2nd, Leunig M, Werlen S, Ganz R. Femoroacetabular impingement and the cam-effect. A MRI-based quantitative anatomical study of the femoral head-neck offset. J Bone Joint Surg Br. 2001;83:171-176.

25. Kim WY, Hutchinson CE, Andrew JG, Allen PD. The relationship between acetabular retroversion and osteoarthritis of the hip. J Bone Joint Surg Br. 2006;88:727-729.

26. Larson CM, Giveans MR. Arthroscopic management of femoroacetabular impingement: early outcomes measures. Arthroscopy. 2008;24:540-546.

27. Laude F, Sariali E, Nogier A. Femoroacetabular impingement treatment using arthroscopy and anterior approach. Clin Orthop Relat Res. 2009;467:747-752.

28. Leunig M, Siebenrock KA, Ganz R. Rationale of periacetabular osteotomy and background work. Instr Course Lect. 2001;50: 229-238.

29. Myers SR, Eijer H, Ganz R. Anterior femoroacetabular impingement after periacetabular osteotomy. Clin Orthop Relat Res. 1999;363:93-99.

30. Neumann M, Cui Q, Siebenrock KA, Beck M. Impingement-free hip motion: the 'normal' angle alpha after osteochondroplasty. Clin Orthop Relat Res. 2009;467:699-703.

31. Notzli HP, Wyss TF, Stoecklin CH, Schmid MR, Treiber K, Hodler J. The contour of the femoral head-neck junction as a predictor for the risk of anterior impingement. J Bone Joint Surg Br. 2002;84:556-560. 
32. Peelle MW, Della Rocca GJ, Maloney WJ, Curry MC, Clohisy JC. Acetabular and femoral radiographic abnormalities associated with labral tears. Clin Orthop Relat Res. 2005;441:327-333.

33. Peters CL, Erickson JA. Treatment of femoro-acetabular impingement with surgical dislocation and débridement in young adults. J Bone Joint Surg Am. 2006;88:1735-1741.

34. Philippon MJ, Briggs KK, Yen YM, Kuppersmith DA. Outcomes following hip arthroscopy for femoroacetabular impingement with associated chondrolabral dysfunction: minimum two-year follow-up. J Bone Joint Surg Br. 2009;91:16-23.

35. Philippon MJ, Stubbs AJ, Schenker ML, Maxwell RB, Ganz R, Leunig M. Arthroscopic management of femoroacetabular impingement: osteoplasty technique and literature review. Am J Sports Med. 2007;35:1571-1580.

36. Philippon MJ, Yen YM, Briggs KK, Kuppersmith DA, Maxwell RB. Early outcomes after hip arthroscopy for femoroacetabular impingement in the athletic adolescent patient: a preliminary report. J Pediatr Orthop. 2008;28:705-710.

37. Reynolds D, Lucas J, Klaue K. Retroversion of the acetabulum. A cause of hip pain. J Bone Joint Surg Br. 1999;81:281288.

38. Tannast M, Goricki D, Beck M, Murphy SB, Siebenrock KA. Hip damage occurs at the zone of femoroacetabular impingement. Clin Orthop Relat Res. 2008;466:273-280. 